\title{
Metode Fuzzy TOPSIS Pada Pengambilan Keputusan Rekrutmen Karyawan PT. Erporate Solusi Global
}

\author{
Ayu Tiara Suci ${ }^{1)}$, Hasyim Asyari2) ${ }^{2}$, Ahmad Yusuf Prasetiawan ${ }^{3)}$, Nasruri Aji Pratomo ${ }^{4)}$ \\ Program Studi Teknik Industri, Fakultas Teknik, Universitas Jenderal Soedirman \\ Jl. Mayor Jenderal Sungkono KM 5 Blater, Purbalingga, 53371, Indonesia ${ }^{1233)}$ \\ E-Mail:ayutiarass@gmail.com ${ }^{1)}$,hasyim.asyari@unsoed.ac.id ${ }^{2}$, \\ ahmad.yusuf.prasetiawan@unsoed.ac.id ${ }^{3)}$
}

\begin{abstract}
ABSTRAK
Sebuah perusahaan berupaya untuk memiliki sumber daya manusia yang berpotensi unggul dan berkualitas tinggi. Pentingnya sumber daya manusia berkualitas tinggi, proses pemilihan karyawan menjadi sangat penting dan perlu dilakukan segera. Penelitian ini dilakukan pada PT. Erporate Solusi Global yang merupakan perusahaan jasa IT dan outsourcing IT. Pemilihan karyawan yang dilakukan belum direpresentasikan secara kuantitatif sehingga masih berdasarkan pandangan dan pemikiran subyektif. Penelitian ini bertujuan untuk memberikan teknik pengambilan keputusan pemilihan karyawan secara kuantitatif melalui metode fuzzy Technique for Order Preference by Similarity to Ideal Solution (TOPSIS). Data diperoleh melalui wawancara dengan CEO dan General Manager untuk mendapatkan bobot kriteria pada tiap tahapan dan diimplementasikan pada kandidat karyawan. Hasil penelitian yang diperoleh adalah perankingan kandidat karyawan untuk tiap tahapan seleksi, sehingga karyawan dinyatakan lulus ke tahap selanjutnya atau gugur dan tidak dapat melanjutkan ke tahap berikutnya. Nilai dengan ranking terendah dan tidak memenuhi kriteria khusus maka akan menghasilkan kandidat gugur. Dari hasil penelitian, penggunaan metode fuzzy dapat mempermudah dalam penilaian subyektif, dan perhitungan fuzzy TOPSIS sampai tahap akhir menghasilkan 2 kandidat lulus dan 1 kandidat yang perlu melakukan test code.
\end{abstract}

Kata kunci: Fuzzy TOPSIS, Pengambilan Keputusan Pemilihan Karyawan, Sistem Gugur tiap Tahapan Seleksi

\section{Fuzzy TOPSIS Method in Employee Recruitment Decision Making at PT. Erporate Solusi Global}

\begin{abstract}
A company aims to have high-quality and high-potential human resources. The importance of high-quality human resources, the process of selecting employees becomes very important and needs to be done immediately. This research was conducted in PT. Erporate Solusi Global which is an IT services and outsourcing company. The current selection of employees has not been represented quantitatively so that it is still based on subjective views and thoughts. This research purpose to provide quantitative employee decision making techniques with Fuzzy Techniques for Order Preference using the Similarity to Ideal Solution (TOPSIS) Method. The data was obtained from interviews with CEO and General Manager to obtain the weight of criteria at each stage and implemented on candidate employees. The results showed the rankings of candidate employees for each stage of selection, so that employees are declared to pass the next stage or fall and cannot proceed to the next stage. Values with the lowest ranking and not according to special criteria will result in candidate failing. The use of fuzzy methods can facilitate subjective assessment, and the calculation of fuzzy TOPSIS to the final stage produces 2 candidates pass and 1 candidate needs to do a test code.
\end{abstract}


Keywords: Fuzzy TOPSIS, Employee Selection Decision Making, Fall System for each Selection Stage

\section{Pendahuluan}

PT. Erporate Solusi Global merupakan perusahaan jasa IT (Information Technology) dan outsource tenaga kerja berbasis IT. Menurut Dita Anindya selaku Manager Keuangan PT. Erporate Solusi Global, outsource tenaga kerja berbasis IT menjadi unggulan dalam perusahaan ini dikarenakan omset yang didapatkan dari outsource berkisar 60\% dari keseluruhan omset yang diperoleh oleh perusahaan. Besarnya prosentase tersebut, membuat perusahaan berupaya terus meningkatkan proses seleksi yang tepat, guna mendapatkan kandidat yang tepat pula.

PT. Erporate Solusi Global membuka lowongan posisi tertentu saja yang dibutuhkan oleh perusahaan yang meminta jasa outsource maupun dari kebutuhan internal perusahaan tersebut. Apabila untuk memenuhi kebutuhan perusahaan lain, maka setelah kandidat terpilih melalui seleksi yang dilakukan PT. Erporate Solusi Global, kemudian kandidat akan diarahkan ke perusahaan lain. Untuk proses rekrutmen dari awal sampai terpilihnya kandidat dilakukan oleh PT. Erporate Solusi Global, untuk selanjutnya tergantung dari kebijakan masing-masing perusahaan apakah akan melakukan proses seleksi lagi atau cukup melihat report dan saran dari PT. Erporate Solusi Global.

Pentingnya proses rekrutmen pada PT. Erporate Solusi Global, mendorong penulis untuk melakukan beberapa peningkatan yang dapat dilakukan dan dapat membantu dalam pengambilan keputusan untuk pemilihan karyawan PT. Erporate Solusi Global. Proses rekrutmen yang dilakukan oleh PT. Erporate Solusi Global dilakukan dengan beberapa tahapan, dimana apabila kandidat tidak lulus maka akan gugur dan tidak dapat melanjutkan ke tahap berikutnya. Pertimbangan keputusan masih dilakukan berdasarkan data yang diperoleh langsung dan belum adanya pertimbangan secara kuantitatif yang dapat menentukan kandidat yang terbaik dalam proses seleksi dan kandidat yang dapat dinyatakan lulus atau gagal. Maka dari itu, perlunya suatu teknik pengambilan keputusan dalam pemilihan karyawan yang dapat dijadikan pengambilan keputusan pemilihan karyawan secara cepat dan tepat. Dengan latar belakang tersebut, perlunya pengembangan pemilihan karyawan dengan mengimplementasikan metode fuzzy TOPSIS (Technique for Order Preference by Similarity to Ideal Solution). Fuzzy TOPSIS dipilih untuk permasalahan tersebut dikarenakan logika fuzzy dalam membuat keputusan pembuat preferensi yang terstruktur (Fisabihillah \& Irawati, 2015). Teori fuzzy membantu dalam konsep mengukur ketidak-jelasan yang berkaitan dengan manusia yang bersifat subjektif. Untuk itu, evaluasi harus dilakukan dalam satu lingkungan. Dalam hal ini, fuzzy mampu membantu untuk memperbaiki kegagalan yang terjadi ketika hanya menggunakan metode TOPSIS saja. Berbeda dengan beberapa penelitian lainnya, penelitian ini dilakukan dengan melakukan perankingan tiap tahapan seleksi, kemudian setiap tahapan akan diperoleh hasil yang dapat lulus ke tahapan selanjutnya sampai dengan terpilih sebagai karyawan. Lingkup penelitian ini adalah hanya ditujukan di PT. Erporate Solusi Global.

Terdapat beberapa artikel dan penelitian mengenai Fuzzy TOPSIS, yaitu Rofiah mengusulkan seleksi penerimaan calon manajer menggunakan fuzzy TOPSIS. Lestari dan Priyodiprodjo mengusulkan seleksi karyawan dengan implementasi fuzzy TOPSIS. Herawatie dan Wuryanto mengusulkan sistem pendukung keputusan pemilihan mahasiswa berprestasi. Mallu mengusulkan sistem pendukung keputusan pemilihan karyawan kontrak menjadi karyawan tetap. Siagian mengusulkan pemilihan karyawan baru menggunakan metode fuzzy TOPSIS. 
Pada penelitian ini, penulis melakukan penelitian dengan judul "Metode Fuzzy TOPSIS pada Pengambilan Keputusan Rekrutmen Karyawan PT. Erporate Solusi Global".

\section{Metodologi}

\subsection{Kerangka Penelitian}

Pengumpulan data dilakukan melalui wawancara dengan pihak perusahaan (HRD, CEO, General Manager PT. Erporate Solusi Global), keterangan referensi perusahaan, buku-buku dan dari hasil observasi ke lapangan selama kerja praktik. Dalam penelitian yang akan dilakukan diperlukan informasi data mengenai objek penelitian. Peneliti berfokus pada kandidat calon karyawan Android Developer, sehingga dibutuhkan data informasi mengenai calon karyawan yang melamar sebagai Android Developer yang berguna sebagai bahan dalam pemecahan masalah, data yang diperlukan yaitu data bobot kriteria seleksi karyawan, data CV karyawan, data nilai yang diberikan pada tiap seleksi karyawan di perusahaan. Android merupakan open source sehingga setiap orang dapat membuat aplikasi untuk Android dan dapat menjualnya di Play Store (Maiyana, 2018). Developer seseorang yang bertugas membangun sebuah sistem, merancang arsitektur, mengimplimentasikan serta mengembangkan sistem tersebut dimasa yang akan mendatang (Firly, 2017).

Setelah data calon karyawan diperoleh, kemudian data diolah menggunakan fuzzy TOPSIS, dimana penilaian bobot dari fuzzy TOPSIS dilakukan oleh General Manager dan CEO pada tahap 1 dan 3, HRD pada tahap 2.

\subsection{Logika Fuzzy}

Logika Fuzzy adalah suatu cara yang tepat untuk memetakan suatu ruang input ke dalam ruang output (Kusumadewi \& Guswaludin, 2005). Logika fuzzy menggunakan ungkapan bahasa untuk menggambarkan nilai variabel. Logika fuzzy bekerja dengan menggunakan derajat keanggotaan dari sebuah nilai yang kemudian digunakan untuk menentukan hasil yang ingin dihasilkan berdasarkan atas spesifikasi yang telah ditentukan. Telah disebutkan sebelumnya bahwa logika fuzzy memetakan ruang input ke ruang output. Antara input dan output ada suatu kotak hitam yang harus memetakan input ke output yang sesuai (Yulmaini, 2015).

Ada beberapa alasan mengapa orang menggunakan logika fuzzy. (Kusumadewi \& Guswaludin, 2005) antara lain :

1. Konsep logika fuzzy mudah dimengerti. Konsep matematis yang mendasari penalaran fuzzy sangat sederhana dan mudah dimengerti.

2. Logika fuzzy sangat fleksibel.

3. Logika fuzzy memiliki toleransi terhadap data-data yang tidak tepat.

4. Logika fuzzy mampu memodelkan fungsi-fungsi nonlinear yang sangat kompleks.

5. Logika fuzzy dapat dibangun dan diaplikasikan berdasarkan pengalamanpengalaman para pakar secara langsung tanpa harus melalui proses pelatihan.

6. Logika fuzzy dapat digunakan pada sistem kendali secara konvensional.

7. Logika fuzzy didasarkan pada bahasa alami.

Fungsi keanggotaan yang digunakan dalam penelitian ini adalah fungsi segitiga. Fungsi segitiga digunakan dalam penelitian ini dikarenakan merupakan fungsi logika dan bentuk sederhana dimana fungsi tersebut menggabungkan 2 garis (linear), seperti yang tertampil pada Gambar 1 .

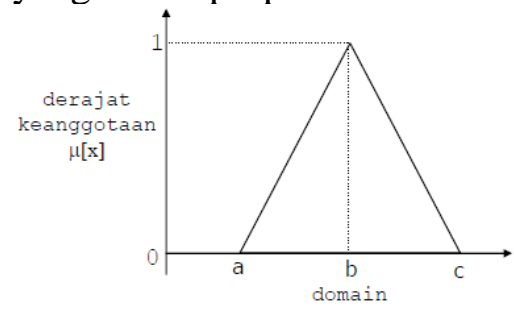

Gambar 1. Kurva Segitiga

Fungsi keanggotaan (Wardhani \& Haerani, 2011) : 


$$
\mu_{x}\left\{\begin{array}{c}
\frac{x-a}{b-a} ; a \leq x \leq b \\
1 ; x=b \\
\frac{c-x}{c-b} ; b \leq x \leq c \\
0 ; x \leq \text { a atau } x \geq c
\end{array}\right.
$$

\subsection{Technique for Order Preference by Similarity to Ideal Solution (TOPSIS)}

Prinsip metode TOPSIS adalah sederhana, dimana alternatif yang dipilih selain memiliki kedekatan dengan solusi ideal positif dan jauh dari solusi ideal negatif (Kusumadewi dkk, 2006). Konsep ini banyak digunakan pada beberapa model MADM untuk menyelesaikan masalah keputusan secara praktis (Kurniawan dkk, 2015).

Metode TOPSIS adalah salah satu metode yang bisa membantu proses pengambilan keputusan yang optimal untuk menyelesaikan masalah keputusan secara praktis (Murnawan \& Siddiq, 2011). Hal ini disebabkan konsepnya sederhana dan mudah dipahami, komputasinya efisien dan memiliki kemampuan untuk mengukur kinerja relatif dari alternatif-alternatif keputusan dalam bentuk matematis yang sederhana (Iriane, 2013).

Secara umum, prosedur dari metode TOPSIS mengikuti langkah-langkah sebagai berikut (Falahah \& Subakti, 2016) :

1. Menentukan matriks keputusan yang ternormalisasi.

$$
r_{i j}=\frac{x_{i j}}{\sqrt{\sum_{i=1}^{m} x_{i j}^{2}}}
$$

dengan $i=1,2 \ldots, \mathrm{m}$ dan $j=1,2, \ldots, \mathrm{n}$.

2. Menghitung matriks keputusan yang ternormalisasi terbobot.

$y_{\mathrm{ij}}=w_{i} r_{i j}$

3. Menghitung matriks solusi ideal positif dan matriks solusi ideal negatif.

$A^{+}=y_{1}{ }^{+}, y_{2}{ }^{+}, \ldots . y_{n}{ }^{+}$

$A^{-}=y_{1}^{-}, y_{2}^{-}, \ldots . y_{n}^{-}$

4. Menghitung jarak antara nilai setiap alternatif dengan matriks solusi ideal positif dan matrik solusi ideal negatif.

$$
\begin{aligned}
& D_{i}^{+}=\sqrt{\sum_{j=1}^{n}\left(y_{i}^{+}-y_{i j}\right)^{2} \ldots \ldots . .(6)} \\
& i=1,2, \ldots . \mathrm{m} \\
& D_{i}{ }^{-}=\sqrt{\sum_{j=1}^{n}\left(y_{i j}-y_{i}^{-}\right)^{2} \ldots .(7)} \\
& i=1,2, \ldots . . \mathrm{m}
\end{aligned}
$$

5. Menghitung nilai preferensi untuk setiap alternatif

$$
V_{i}=\frac{D_{i}^{-}}{D_{i}^{-}-D_{i}^{+}}
$$

\section{Hasil dan Pembahasan \\ 3.1. Pengumpulan Data}

Kegiatan penelitian yang terpenting adalah pengumpulan data (Afrizal, 2014). Tahap seleksi karyawan terdiri dari 3 tahap. Tahap pertama adalah tahap biodata dimana kandidat mengirimkan $\mathrm{CV}$ biodata ke perusahaan. Apabila biodata memenuhi kriteria maka kandidat lulus, dan apabila masih terdapat informasi yang ingin digali secara umum, maka kandidat akan diberikan validation test (berisi mengenai pertanyaan dasar terkait dengan profesi yang dilamar). Kemudian tahap selanjutnya adalah tahap interview personality. Tahap yang terakhir adalah tahap interview technical. Apabila kandidat dinilai kurang pada interview technical, maka kandidat akan diberikan test code. Pada penelitian ini, validation test dan test code tidak dilakukan perhitungan dan analisinya dikarenakan validation test dan test code berperan sebagai data pelengkap pada 3 tahapan utama seleksi karyawan. Validation test tidak menjadi dasar untuk menggugurkan karyawan, sedangkan test code dapat menjadi penilaian karyawan gugur, namun merupakan penilaian akhir dan berisifat pribadi bagi perusahaan. Penelitian ini terbatas sampai tahap interview technical, dan hanya mengantarkan kandidat menuju test code. Tahap seleksi karyawan PT. Erporate Solusi Global disajikan pada Gambar 2.

Berikut ini merupakan data bobot kriteria dan bobot alternatif yang diperoleh 
dari hasil wawancara dengan CEO dan General Manager.

Terdapat kriteria khusus yang harus dipenuhi. Kriteria khusus digunakan sebagai syarat maksimal tiap tahapan, apabila kandidat tidak memenuhi kriteria khusus maka kandidat dapat dinyatakan gagal.

\subsection{Pengolahan Data}

Pengolahan data merupakan tahap dimana data diolah sesuai dengan prosedur yang telah dimasukan (Mahyuni dkk, 2014). Pengolahan data adalah suatu proses menerima data sebagai masukan (input) memproses (processing) menggunakan proses tertentu, dan mengeluarkan hasil proses data tersebut dalam bentuk informasi/output (Yulansari, 2013). Pengolahan data pada penelitian ini dilakukan dengan memberikan nilai bobot alternatif/ratings dan bobot kriteria berdasarkan logika fuzzy. Skala yang digunakan yaitu 1 sampai 9.Perbandingan berpasangan yang dilakukan menggunakan skala nilai 1-9 sebelum skala tersebut dikonversikan kedalam nilai triangular fuzzy number/TFN (Jang dkk, 1997). Rating Fuzzy dapat dilihat pada Tabel 3. Kurva segitiga yang diterapkan pada penelitian ini disajikan pada Gambar 3. dan Gambar 4.

Tabel 1. Penilaian Bobot Kriteria Tahap Seleksi

\begin{tabular}{|c|c|c|}
\hline Tahap & Kriteria & Bobot \\
\hline 1. Biodata & $\begin{array}{l}\text { Skill } \\
\text { Pengalaman } \\
\text { kerja }\end{array}$ & $\begin{array}{c}\text { medium } \\
\text { high }\end{array}$ \\
\hline $\begin{array}{l}\text { 2. Interview } \\
\text { Personality }\end{array}$ & $\begin{array}{l}\text { General } \\
\text { Information } \\
\text { Motivasi } \\
\text { Kepribadian } \\
\text { Kepemimpinan } \\
\text { Teamwork } \\
\text { Bekerja di } \\
\text { bawah tekanan } \\
\text { Manajemen } \\
\text { konflik } \\
\text { Finishing }\end{array}$ & $\begin{array}{c}\text { low } \\
\text { low } \\
\text { low } \\
\text { low } \\
\text { medium } \\
\text { High } \\
\text { medium }\end{array}$ \\
\hline $\begin{array}{l}\text { 3. Interview } \\
\text { Technical }\end{array}$ & $\begin{array}{l}\text { Kemampuan } \\
\text { Level coding }\end{array}$ & $\begin{array}{l}\text { High } \\
\text { High }\end{array}$ \\
\hline
\end{tabular}

Tabel 2. Kriteria Khusus Tiap Tahapan Seleksi

\begin{tabular}{|c|c|c|}
\hline No & Tahapan & $\begin{array}{c}\text { Kriteria yang harus } \\
\text { Dipenuhi }\end{array}$ \\
\hline 1 & Biodata & $\begin{array}{l}\text { - Latar belakang } \\
\text { pendidikan berbasis IT } \\
\text { - Memiliki skill terkait } \\
\text { profesi yang dilamar }\end{array}$ \\
\hline 2 & $\begin{array}{l}\text { Interview } \\
\text { Personality }\end{array}$ & $\begin{array}{l}\text { - Manajemen } \\
\text { yang baik }\end{array}$ \\
\hline 3 & $\begin{array}{l}\text { Interview } \\
\text { Technical }\end{array}$ & $\begin{array}{ll}\text { - Pengalaman dan skill } \\
\text { dapat disampaikan } \\
\text { secara jelas dan } \\
\text { terpercaya }\end{array}$ \\
\hline
\end{tabular}

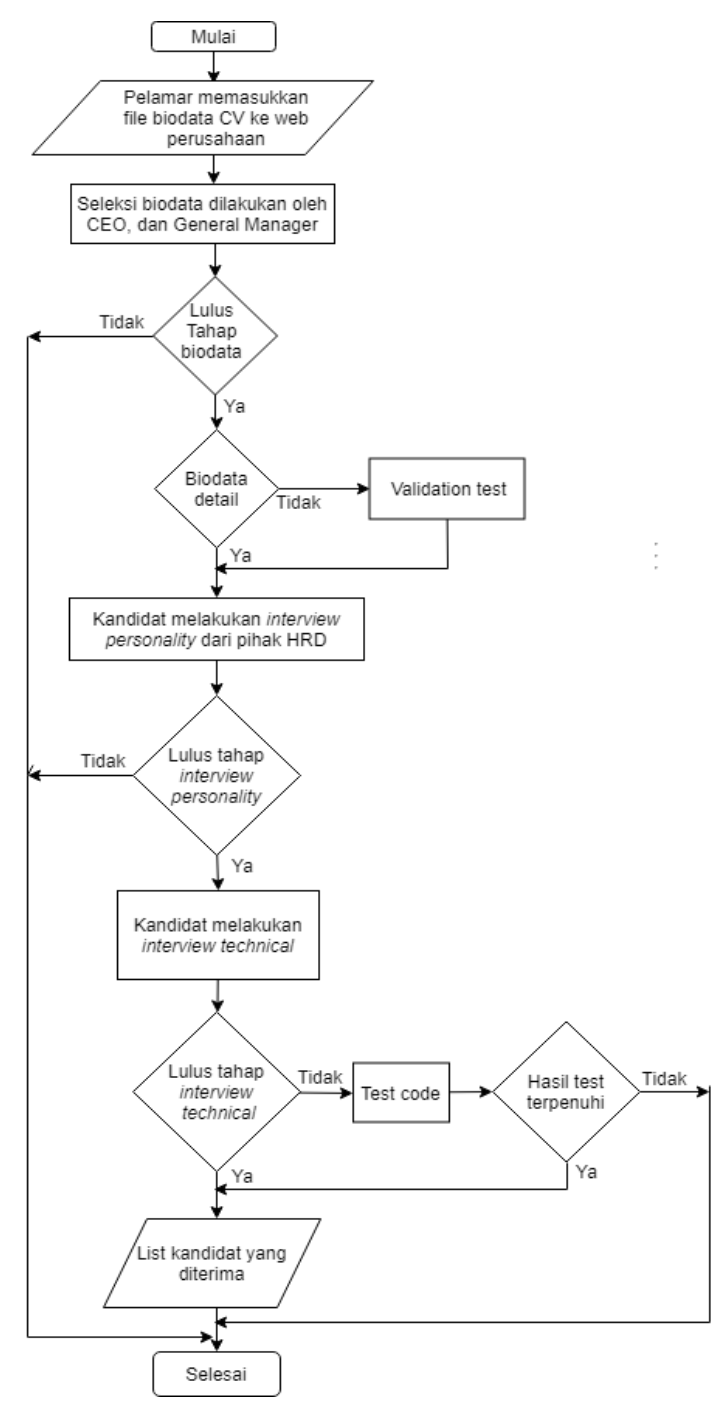

Gambar 2. Flowchart Proses Seleksi Karyawan PT. Erporate Solusi Global dengan Sistem Gugur 
Tabel 3. Rating Fuzzy

\begin{tabular}{ccc}
\hline $\begin{array}{c}\text { Fuzzy } \\
\text { Number }\end{array}$ & $\begin{array}{c}\text { Bobot } \\
\text { Alternatif/Ratings }\end{array}$ & $\begin{array}{c}\text { Bobot } \\
\text { Kriteria }\end{array}$ \\
\hline$(1,1,3)$ & Very Poor $($ VP) & Very Low $($ VL $)$ \\
$(1,3,5)$ & Poor $(P)$ & $\operatorname{Low}(L)$ \\
$(3,5,7)$ & Fair $(F)$ & Medium $(M)$ \\
$(5,7,9)$ & $\operatorname{Good}(G)$ & $\operatorname{High}(H)$ \\
$(7,9,9)$ & $\operatorname{Very} \operatorname{Good}(V G)$ & $\begin{array}{c}\text { Very High } \\
(\text { VH })\end{array}$ \\
\hline
\end{tabular}

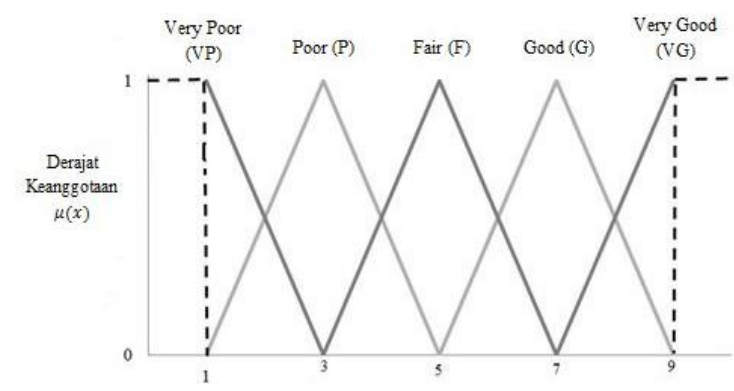

Gambar 3. Linguistik Bobot Alternatif/Ratings Menggunakan Kurva Segitiga

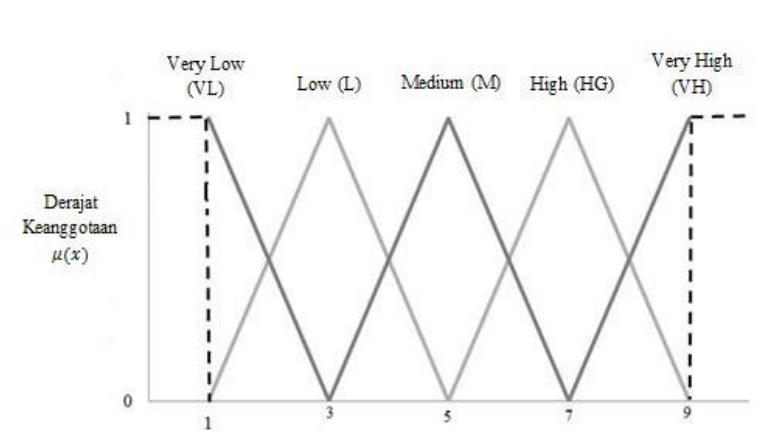

Gambar 4. Linguistik Bobot Kriteria Menggunakan Kurva Segitiga

Tabel 4. Bobot Alternatif Tahap Biodata

\begin{tabular}{ccccccc}
\hline Kriteria & A1 & A2 & A3 & A4 & A5 & A6 \\
\hline C11 (Skill) & F & G & VP & G & P & VP \\
C12 & & & & & & \\
$\begin{array}{c}\text { (Pengalaman } \\
\text { kerja) }\end{array}$ & G & P & P & G & P & VP \\
\hline
\end{tabular}

Tahap pertama penilaian bobot alternatif dilakukan oleh CEO atau oleh General Manager, kemudian dilakukan perhitungan fuzzy TOPSIS. Berikut ini adalah bobot alternatif pada tiap kandidat pada tahap biodata.

Tahap kedua yaitu interview personality, bobot alternatif diberikan oleh HRD kemudian dilakukan perhitungan fuzzy TOPSIS. Berikut ini bobot alternatif tahap interview personality, yang terdiri dari kandidat yang lulus tahap pertama.

Tahap ketiga yaitu interview technical dilakukan oleh Teknisi ahli profesi Android Developer kemudian dilakukan perhitungan fuzzy TOPSIS. Berikut ini adalah bobot alternatif pada kandidat yang lulus tahap kedua dan telah melakukan interview technical.

Tabel 5. Bobot Alternatif Tahap Interview Personality

\begin{tabular}{|c|c|c|c|c|}
\hline Kriteria & A1 & $\mathbf{A 2}$ & A4 & A5 \\
\hline $\begin{array}{l}\text { C21 (General } \\
\text { Information) }\end{array}$ & G & $\mathrm{F}$ & G & $\mathrm{P}$ \\
\hline C22 (Motivasi) & $\mathrm{F}$ & G & $\mathrm{G}$ & $\mathrm{F}$ \\
\hline C23 (Kepribadian) & G & G & $\mathrm{F}$ & G \\
\hline C24 (Kepemimpinan) & G & $\mathrm{F}$ & $\mathrm{G}$ & $\mathrm{F}$ \\
\hline C25 (Teamwork) & $\mathrm{G}$ & $\mathrm{G}$ & $\mathrm{G}$ & $\mathrm{F}$ \\
\hline $\begin{array}{c}\text { C26 (Bekerja di bawah } \\
\text { tekanan) }\end{array}$ & $\mathrm{G}$ & $\mathrm{G}$ & G & $\mathrm{G}$ \\
\hline C27 (Manajemen konflik) & $\mathrm{F}$ & $\mathrm{F}$ & $\mathrm{G}$ & VP \\
\hline C28 (Finishing) & G & $\mathrm{G}$ & G & $\mathrm{F}$ \\
\hline
\end{tabular}

Tabel 6. Bobot Alternatif Tahap Interview Technical

\begin{tabular}{cccc}
\hline Kriteria & A1 & A2 & A4 \\
\hline C31 (Kemampuan) & G & G & G \\
C32 (Level Coding) & G & M & VG \\
\hline
\end{tabular}

Bobot alternatif yang diberikan oleh decision maker, yaitu CEO, General Manager, HRD, dan Teknisi kemudian dijadikan dasar perhitungan TOPSIS pada tiap tahapan seleksi. 
Pada perhitungan fuzzy TOPSIS tahapan dalam penelitian ini, tiap tahapan seleksi terdapat kandidat lulus dan kandidat gugur. Kandidat dinyatakan lulus dilihat bukan dari nilainya melainkan hasil ranking kandidat, apabila kandidat berada di ranking bawah dan tidak memenuhi kriteria khusus maka kandidat dinyatakan gagal. Kriteria khusus dan posisi ranking menyatakan kandidat dapat lulus ke tahap berikutnya atau tidak.

\subsection{Hasil}

\subsubsection{Tahap Biodata}

Tahap biodata untuk posisi Android Developer terdiri dari 6 kandidat. Pada tahap ini, kriteria khusus yang utama dan menjadi syarat utama adalah kandidat memiliki latar belakang IT baik berdasarkan studinya, atau berdasarkan pengalaman yang telah dilakukan. Hasil yang diperoleh dari pengolahan data pada tahap biodata adalah berikut ini.

Tabel 7. Hasil Tahap Biodata

\begin{tabular}{cccc}
\hline Ranking & Alternatif & Nilai Preferensi & Status \\
\hline 1 & A4 & 0,305 & LULUS \\
2 & A1 & 0,206 & LULUS \\
3 & A2 & 0,090 & LULUS \\
4 & A5 & 0,036 & LULUS \\
5 & A3 & 0,027 & GAGAL \\
6 & A6 & 0,006 & GAGAL \\
\hline
\end{tabular}

Kandidat A4, A1, A2, dan A5 dinyatakan lulus dikarenakan memenuhi syarat utama latar belakang IT dan tidak berada di ranking terendah artinya kriteria lainnya memiliki nilai bobot yang tinggi. Sedangkan kandidat A3 dan A6 dinyatakan gagal pada tahap biodata dikarenakan berada di ranking terbawah dan tidak memenuhi kriteria khusus yaitu kandidat tersebut tidak memiliki latar belakang IT baik dari pengalaman maupun studinya. Kandidat lainnya dinyatakan lulus dikarenakan memenuhi kriteria khusus dan tidak menempati peringkat bawah.

Kandidat yang lulus pada tahap biodata kemudian mengisi validation test yang berisi mengenai data-data umum untuk menggali pengetahuan dan pengalaman kandidat terkait posisi Android Developer. Untuk selanjutnya, kandidat akan dijadwalkan melakukan tahap selanjutnya yaitu Interview Personality.

\subsubsection{Tahap Interview Personality}

Tahap ini merupakan tahap lanjutan setelah kandidat lulus dari tahap pertama yaitu tahap biodata. Kandidat dapat melakukan Interview Personality secara online maupun secara langsung dengan menghadiri kantor PT. Erporate Solusi Global. Kriteria khusus yang menjadi hal utama pertimbangan pada tahap ini adalah caranya dalam manajemen konflik. Berikut ini merupakan hasil ranking pada tahap Interview Personality.

Kandidat A4, A1 dan A2 dinyatakan lulus dikarenakan memenuhi kriteria utama dan tidak berada di ranking terendah. Kandidat A5 dinyatakan gagal dikarenakan tidak dapat memenuhi kriteria utama interview personality dan menempati ranking terendah pada penilaian ini. Kandidat yang lulus kemudian dijadwalkan untuk melakukan Interview Technical.

\begin{tabular}{cccc}
\multicolumn{4}{c}{ Tabel 8. Hasil Tahap Interview Personality } \\
\hline Ranking & Alternatif & Nilai Preferensi & Status \\
\hline 1 & A4 & 0,526 & LULUS \\
2 & A1 & 0,456 & LULUS \\
3 & A2 & 0,438 & LULUS \\
4 & A5 & 0,239 & GAGAL
\end{tabular}

\subsubsection{Tahap Interview Technical}

Kandidat yang lulus pada tahap Interview Personality kemudian melakukan Interview Technical. Interview ini menggali secara teknis kemampuan yang dimiliki oleh kandidat berdasarkan profesi yang dilamar, pada penelitian ini profesi yang diteliti adalah Android Developer. Berikut ini merupakan hasil ranking pada tahap Interview Technical. 
Tabel 9. Hasil Tahap Interview Technical

\begin{tabular}{cccc}
\hline Ranking & Alternatif & Nilai Preferensi & Status \\
\hline 1 & A4 & 0,620 & LULUS \\
2 & A1 & 0,435 & LULUS \\
3 & A2 & 0,369 & TC \\
\hline
\end{tabular}

Kandidat A4 dan A1 berada di 2 peringkat teratas dan dinyatakan lulus dikarenakan dapat memenuhi kriteria utama yaitu menyampaikan kemampuan secara jelas dan nyata, sedangkan untuk kandidat A2 dinyatakan belum lulus dikarenakan belum dapat menyampaikan kemampuan secara jelas dan nyata sehingga dialihkan ke test code. Kandidat yang sudah melalui tahapan ini, saat interview technical dinyatakan kurang memadai, maka dialihkan menuju test code dan dalam tes tersebut hasilnya dapat ditentukan apakah kandidat akan lulus atau tidak, perlu adanya pelatihan, atau dapat dialihkan menuju profesi lainnya yang dibutuhkan oleh perusahaan.

\section{Kesimpulan}

Fungsi segitiga berbobot yang digunakan memberikan peningkatan obyektivitas penilaian pemilihan karyawan, dengan skala yang digunakan 1-9 yang kelompok notasinya yaitu $(1 ; 1 ; 3),(1 ; 3 ; 5),(3 ; 5 ; 7),(5 ; 7 ; 9),(7 ; 9 ; 9)$ terdiri dari bobot kriteria (very low, low, medium, high, very high) dan bobot alternatif/ratings (very poor, poor, fair, good, very good). Dari hasil perhitungan yang dilakukan dengan menggunakan metode fuzzy TOPSIS, didapatkan hasil pada tahap pertama kandidat yang lulus yaitu A1, A2, A4, dan A5 sedangkan pada tahap kedua 3 kandidat yang lulus yaitu A1, A2, dan A4, tahap terakhir 2 kandidat dinyatakan lulus yaitu A1 dan A2 sedangkan kandidat ketiga belum lulus dan diberikan test code. Kriteria khusus dan ranking terendah pada setiap tahapan menjadi hal yang utama untuk mempertimbangkan kandidat lulus atau gagal.

\section{Daftar Pustaka}

Afrizal. (2014). Metode Penelitian Kualitatif. Jakarta: Rajawali Pers.
Falahah, \& Subakti, R. (2016). Penerapan Metoda TOPSIS pada Analisis Penentuan Posisi Ideal Pemain Sepak Bola. Seminar Nasional Aplikasi Teknologi Informasi (SNATi), ISSN: 1907-5022.

Firly, N. (2017). Android Application Development for Rookies with Database. Jakarta: Elex Media Komputindo.

Fisabihillah \& Irawati DA. (2015). Sistem Pendukung Keputusan Pemberian Bonus Tahunan Pada Karyawan Dengan Metode Fuzzy-Topsis. Prosiding Seminar Informatika Aplikatif Polinema 2015.

Iriane, GR., Ernawati., \& Wisnubhadra, I. (2013). Analisis Penggabungan Metode SAW dan Metode Topsis untuk Mendukung Keputusan Seleksi Penerimaan Dosen. Seminar Nasional Informatik, Vol 1, No.4.

Jang J.S.R., Sun C.T., \& Mizutani E. (1997). NeuroFuzzy and soft computing a computational approach to learning and machine intelligence. US: Prentice Hall.

Kurniawan, E., Mustafidah H., \& Shofiyani, A. (2015). Metode TOPSIS untuk Menentukan Penerimaan Mahasiswa Baru Pendidikan Dokter di Universitas Muhammadiyah Purwokerto. JUITA ISSN: 2086-9398, Vol. 3, No.4.

Kusumadewi, S \& Guswaludin, I. (2005). Fuzzy Multi-Criteria Decision Making. Media Informatika, Vol. 3 No.1., 25-38.

Kusumadewi, S., Hartati, S., Harjoko, A., \& Wardoyo, R. (2006). Fuzzy Multi-Atribute Decision Making (Fuzzy MADM). Yogyakarta: Graha Ilmu.

Mahyuni, Sharipuddin, \&Martono. (2014). Perancangan Sistem Pengolahan Data Pada SMA Negeri 6 Kabupaten Tebo. Jurnal Ilmiah Media SISFO, Vol.8 No.3.

Maiyana, F. (2018). Pemanfaatan Android dalam Perancangan Aplikasi Kumpulan Doa. Research of Science and Informatic, Vol. 4, I1.,54-67.

Murnawan, E., Siddiq, AF. (2011). Sistem Pendukung Keputusan Menggunakan Metode Technique for Order by Similarity to Ideal Solution (TOPSIS). KNTIA 2011. 
Wardhani, LK. \& Haerani, E. (2011). Analisis Pengaruh Pemilihan Fuzzy Membership Function Terhadap Output Sebuah Sistem Fuzzy Logic. SNTIKI III 2011.

Yulansari, K. (2013). Sistem Informasi Pengolahan Data Iuran Badan Pembantu Penyelenggaraan Pendidikan Sekolah Menengah Kejuruan Negeri 2 Donorojo. Seruni-Seminar Riset Unggulan Nasional Inoformatika dan Komputer, Vol. 2, No.1. Yulmaini. (2015). Penggunaan Metode Fuzzy Inference System (FIS) Mamdani Dalam Pemilihan Peminatan Mahasiswa Untuk Tugas Akhir. Jurnal Informatika, Vol. 15, No.1. 